\title{
Evaluating QT dispersion in children with syncope attacks
}

\author{
Amir Hossein Movahedian ${ }^{1}$, Ali Mohammad Shakiba ${ }^{2}$, Mojtaba Sehat ${ }^{3}$, Maryam Sadat Razavi ${ }^{4}$, Marzieh \\ Heydarzadeh Arani ${ }^{\star 2}$
}

\author{
${ }^{1}$ Department of Pediatric Cardiology, Tehran University of Medical Sciences, Tehran, Iran \\ ${ }^{2}$ Department of Pediatrics, Kashan University of medical sciences, Kashan, Iran \\ ${ }^{3}$ Department of Community Medicine, Kashan University of medical sciences, Kashan, Iran \\ ${ }^{4}$ Kashan University of medical sciences, Kashan, Iran
}

\author{
Corresponding Author: Marzieh Heydarzadeh Arani \\ Department of Pediatrics, Kashan University of medical sciences, Kashan, Iran, Qotbe Ravandi Blvd., Kashan, Iran \\ Email: mmousavi1350@yahoo.com, Phome: +98 9131631910 , Fax: +98 3155540021
}

Cite this article as: Movahedian AH, Shakiba AM, Sehat M et.al Evaluating QT dispersion in children with syncope attacks. Nepalese Heart Journal 2018; 15(2): 15-19.

Received date: $16^{\text {th }}$ June 2018

Accepted date: $21^{\text {st }}$ August 2018

\section{Abstract}

Background and Aims: Syncope is due to brain dysfunction and is a common compliant among children. It accounts for almost 3\% of all emergency departments (ED) visits. The aim of this study was to evaluate the QT dispersion in children with syncope in Shahid Beheshti Hospital of Kashan in 2014.

Methods: This was a descriptive cross-sectional study performed among 50 children with syncope attacks (case group) referred to the Clinic of Shahid Beheshti Hospital in Kashan during 2014 and 50 healthy children (control group) referred to the center for causes such as a cold or developmental examination. ECG was taken and QT, QTd (QT dispersion), QTc (Corrected QT interval) and QTcd (QTmin-QTmax =QT dispersion) intervals were studied. After proper explanation to the parents, data was obtained from the case and control group and was analyzed using Chisquare, Mann-Whitney, Kolmogorov-Smirnov, Levene>s, Kruskal-Wallis statistical tests.

Results: Total, there were 100 children in the study, the participants were divided into two groups of case $(\mathrm{n}=50)$ and control $(\mathrm{n}=50)$. Among the studied children, a total of 46 of them $(46 \%)$ were boys. The mean age range of children in the case and control groups were $7.73 \pm 2.33$ and $8.09 \pm 2.31$ years, respectively (P-value 0.440 ). The mean QTmax, QTcmax, QTd and QTcd in the case group were $348.80 \pm 46.93,464.94 \pm 48.71,47.80 \pm 19.72,68.36 \pm 24.59$ $\mathrm{ms}$ (millisecond) respectively and $305.28 \pm 35.52,395.70 \pm 50.05,29.68 \pm 13.45$, and $45.16 \pm 24.46 \mathrm{~ms}$ respectively in the control group. There was a significant difference in terms of each of the 4 parameters $(\mathrm{P}<0.001)$, and the value of indices in the control group was significantly less than that of the patient group.

Conclusion: According to the results of the study, the QTd and QTcd values in the children with syncope attacks were higher than those in the control group. Therefore, precise ECG examination in children suspected of syncope attacks can be helpful in confirming the incidence of syncope. Additionally, the recurrence of attacks can also be predicted in children with higher QTd and QTcd values.

Keywords: QT interval, QTd dispersion, QTcd dispersion, Syncope.

DOI: http://dx.doi.org/10.3126/njh.v15i2.21471

\section{Introduction}

Syncope is a common symptom present in about $1-2 \%$ of emergency visits ${ }^{1,2}$. However, the etiology of most attacks is unknown. Recently, using Head-up tilt test (HUT) to diagnose the cases with unknown etiologies has led to decreased incidence of undiagnosed syncope $e^{3-7}$. Cardiovascular diseases are the main causes of syncope in adults ${ }^{8,9}$. In adolescents and children with syncope attacks, neurological diseases account for 50$66 \%$ of cases; in other words, NMS (neurological -mediated syncope) is the most common type in adolescents and children? Less than $50 \%$ of the syncope cases occur in children due to ventricular tachycardia ${ }^{10}$. Some studies have shown that it is age-dependent $t^{11-12}$. The cardiac causes being detected by electrocardiogram (ECG) include arrhythmias and acute coronary syndrome (ACS). There are many studies in this regard that examine the morphology of QRS to determine the prognosis of the attacks in the affected patients ${ }^{13}$. ECG parameters increasing the mortality rate in patients with cardiovascular diseases include

@Nepalese Heart Journal. Nepalese Heart Journal retains copyright and work is simultaneously licensed under Creative Commons Attribution License CC - BY 4.0 that allows others to share the work with an acknowledgement of the work's authorship and initial publication in this journal. 
QRS interval, QRS-T angle and QTC (Corrected QT Interval), QTC dispersion, and heart rate changes ${ }^{14-21}$. Factors increasing the chance of arrhythmias can be directly evaluated by ECG and by measuring changes in QT intervals between different QT dispersions (QTd). QTd can be obtained by determining the time difference between QTmax and QTmin (QTminQTmax = QTd). QTd is a reflection of the heterogeneity of cardiac repolarization, and its increase indicates the potential for ventricular arrhythmias and sudden cardiac death ${ }^{22-25}$. QT is one of the factors that has been evaluated as a predictor of mortality in various diseases, including diabetes mellitus, congestive heart failure $(\mathrm{CHF})^{26-29}$.Unfortunately, few studies are carried out to determine the relationship between QT and syncope attacks. A study performed by J Haop et al.(2010) on children with syncope, ADHD (Attention Deficit Hyperactivity Disorder), and epilepsy demonstrated that the prevalence rate of prolonged QT interval in patients with epilepsy, syncope attacks and ADHD was $14 \%, 4 \%$ and $2 \%$ respectively. ${ }^{30}$ The aforementioned study emphasized that ECG should be routinely performed on patients with epilepsy and syncope to recognize the etiology and to adopt preventive measures for the children ${ }^{30,31}$. Nancy Colman et al. (2009) also conducted a study on 32 patients with prolonged QT interval and 69 patients with vasovagal syncope, all of whom was younger than 40 years of age, and the results revealed that having a family history of syncope and sudden death due to cardiovascular diseases was more common in patients with prolonged QT interval and, on the other hand, standing posture, as a risk factor for syncope, was more frequently found in patients with vasovagal syncope ${ }^{32}$.

QT dispersion can be regarded as a predictive factor for syncope in individuals not having the history of syncope, prolonged QT interval or abnormal QT morphology and QT dispersion can have a role in determining the prognosis of patients with syncope attacks. Considering that there are lack of studies on the QT dispersion in children with syncope attacks, the present study attempted to investigate QT dispersion in children with syncope attacks in Kashan, Iran.

\section{Materials and methods:}

This was a descriptive-analytical study performed prospectively from the beginning of 2014 to the end of 2014. The candidates included all children having a syncope attack and referred to Shahid Beheshti Clinic in Kashan for treatment and follow up. Using consecutive sampling method, patients were selected. The inclusion criteria encompassed the occurrence of syncope attack; the age range between 3 months to 15 years of old; the height and weight, and $\mathrm{Hb}$ levels percentile between the 5 to $95 \%$. Exclusion criteria included infants less than 3 months of age and more than 15 years of old; abnormal Hb levels, height and weight less than $5 \%$ and more than $95 \%$; a disease or drug use leading to the acquired and secondary increase in the QT interval, as well as any conditions leading to decreased consciousness level e.g. epilepsy, dizziness, hypoglycemia, head trauma, coma and shock. ECG was taken from all the patients and QT intervals, minimum and maximum, QTc, QTd and QTcd were measured and recorded by using 12-lead ECG, each of which contains at least multiple ECGs with at least 3 different heart rates using a ruler and magnifying glass. Pediatric heart specialists performed the echocardiography using the echocardiography device (HDI$3500 \mathrm{cv}$ ) to evaluate heart disease in the case group. The syncope was defined as a sudden onset of attacks, short duration and rapid and continuous recovery of the attack. Out of the children referred to the clinic for a routine visit, 50 healthy children were selected and were matched with the case group in terms of age and gender. ECG was also taken from the participants.
After measuring the QTmin and QTmax, QTc, QTd and QTcd were measured and recorded. The related tables and charts were drawn using the results. The control and case groups were compared regarding the effects of QT intervals on the incidence of the attacks. After obtaining the parent's consent, explaining the project to them and obtaining written informed consent, the children of both case and control groups were included in the study. Also blood test, ECG and echocardiography were done. After collecting data; QT and QTc, QTd and QTcd indicators (mean and SD) were calculated in two groups and were analyzed using t-test, Kolmogorov-Simonov, Mann-Whitney U, Levene's, Kruskal-Wallis and Chi-square.

\section{Findings}

This study showed that 23 (46\%) of the children in the case group and $54 \%$ of control groups were male respectively. The statistical analysis based on Chi square test showed that there was no significant difference between two groups in terms of gender distribution $(\mathrm{P}=0.545)$. The mean age ranges in children in case and control groups were 7.73 and 8.09 years respectively. The statistical analysis based on Independent t-test showed that there was no significant difference between two groups in terms of age distribution $(\mathrm{P}=0.440)$. The mean of hemoglobin levels in children in case and control groups was 11.84 and $11.79 \mathrm{mg} /$ deciliter respectively. The statistical analysis based on Independent t-test showed that there was no significant difference between the groups in terms of distribution of hemoglobin levels $(\mathrm{P}=0.849)$.

The mean PR interval dispersions in children in case and control groups were 137.80 and $134.80 \mathrm{~ms}$ respectively. The statistical analysis based on Mann-Whitney $U$ test showed that there was no significant difference between the groups in terms of $\mathrm{PR}$ interval dispersion $(\mathrm{P}=0.466)$. As shown in the table 1 , the mean QTd interval in the case group was significantly more than that in the control group. The statistical analysis based on Mann-Whitney u test showed that there was a comprehensible difference in this regard $(\mathrm{P}<0.001)$.

Table 1: The comparison of QTd in the case and control groups

\begin{tabular}{|c|c|c|c|}
\hline & \multicolumn{2}{|c|}{ QTd [ms] } & \multirow{11}{*}{$\begin{array}{l}\mathrm{P}^{*} \\
<0.001\end{array}$} \\
\hline & $\begin{array}{l}\text { syncope } \\
\text { group }\end{array}$ & $\begin{array}{l}\text { healthy } \\
\text { group }\end{array}$ & \\
\hline Number & 50 & 50 & \\
\hline Mean & 47.80 & 29.68 & \\
\hline Standard Deviation & 19.72 & 13.45 & \\
\hline Median & 40.00 & 30.00 & \\
\hline Mode & 40.00 & 30.00 & \\
\hline Minimum & .00 & .00 & \\
\hline Maximum & 90.00 & 50.00 & \\
\hline Percentile 25 & 40.00 & 25.00 & \\
\hline Percentile 75 & 60.00 & 40.00 & \\
\hline
\end{tabular}

QTd: $Q T$ interval dispersion, $P^{*}$ Mann-Whitney test

The table 2 indicates that the mean QTcd interval in the case and control groups were $68.36 \pm 24.59$ and $45.16 \pm 22.46 \mathrm{~ms}$ respectively. As displayed in the table, the mean QTed interval was significantly less in the control group than that in the case group. The statistical analysis based on Mann-Whitney $U$ test showed that there was a significant difference between the case and control groups in terms of mean QTed interval $(\mathrm{P}<0.001)$. 


\begin{tabular}{|c|c|c|c|}
\hline & \multicolumn{2}{|c|}{ QTd [ms] } & \multirow{11}{*}{$\begin{array}{l}\mathrm{P}^{*} \\
<0.001\end{array}$} \\
\hline & $\begin{array}{l}\text { syncope } \\
\text { group }\end{array}$ & $\begin{array}{l}\text { healthy } \\
\text { group }\end{array}$ & \\
\hline Number & 50 & 50 & \\
\hline Mean & 68.36 & 45.16 & \\
\hline Standard Deviation & 24.59 & 22.46 & \\
\hline Median & 70.50 & 47.50 & \\
\hline Mode & .00 & 50.00 & \\
\hline Minimum & .00 & .00 & \\
\hline Maximum & 104.00 & 85.00 & \\
\hline Percentile 25 & 55.00 & 34.00 & \\
\hline Percentile 75 & 88.00 & 59.00 & \\
\hline
\end{tabular}

$P^{*}$ Mann-Whitney testQTcd: Corrected QT interval dispersion

The mean QTmin interval in the control group was significantly less than that in the case group. The statistical analysis based on Mann-Whitney $U$ test showed that there was a significant difference between the children in the case and control groups in terms of mean QTmin intervals $(\mathrm{P}<0.001)$. The mean QTmax interval in the control group was significantly less than that in the case group The statistical analysis based on Mann-Whitney $U$ test showed that there was a significant difference between the groups in terms of mean QTmax intervals $(\mathrm{P}<0.001)$. (Table 3$)$ As the table 4 showed, the mean QTCmin interval in the control group was significantly less than that in the case group. The statistical analysis based on Mann-Whitney $U$ test demonstrated that there was significant difference between the groups in terms of mean QTCmin intervals $(\mathrm{P}<0.001)$. The mean QTCmax interval in the control group was also significantly less than that in the case group. Based on MannWhitney $U$ test, the statistical analysis showed that there was a significant difference between the groups in terms of mean QTCmax intervals $(\mathrm{P}<0.001)$.

The difference in decreased QT d intervals varied from 18 to $17.5 \mathrm{~s}$ (second) even after matching with all variables. It was meant that all studied variables couldn't have a significant effect on the relationship between syncope attacks and QTd levels $(\mathrm{P}<0.261)$.

\begin{tabular}{|c|c|c|c|c|c|c|c|}
\hline & \multirow[t]{2}{*}{ Model } & \multicolumn{2}{|c|}{$\begin{array}{l}\text { Non standardized } \\
\text { Coefficients }\end{array}$} & \multirow{2}{*}{$\begin{array}{c}\text { Standardized } \\
\text { Coefficients } \\
\text { Beta }\end{array}$} & \multirow[t]{2}{*}{$\mathrm{t}$} & \multirow[t]{2}{*}{ Sig. } & \multirow{9}{*}{$\begin{array}{c}\mathrm{R}^{2} \\
0.261\end{array}$} \\
\hline & & B & $\begin{array}{l}\text { Std. } \\
\text { Error }\end{array}$ & & & & \\
\hline \multirow{7}{*}{1} & (Constant) & 23.238 & 33.210 & & .700 & .486 & \\
\hline & group & -23.584 & 4.814 & -.453 & -4.899 & .000 & \\
\hline & sex & 5.522 & 4.855 & .105 & 1.137 & .258 & \\
\hline & age & -1.906 & 2.084 & -.169 & -.914 & .363 & \\
\hline & BMI & 1.850 & 1.631 & .209 & 1.134 & .260 & \\
\hline & PR & .115 & .141 & .076 & .817 & .416 & \\
\hline & $\mathrm{Hb}$ & .676 & 1.851 & .034 & .365 & .716 & \\
\hline
\end{tabular}

$P^{*}$ Multi linear regression

\begin{tabular}{|c|c|c|c|c|c|c|c|}
\hline & \multirow[t]{2}{*}{ Model } & \multicolumn{2}{|c|}{$\begin{array}{l}\text { Non standardized } \\
\text { Coefficients }\end{array}$} & \multirow{2}{*}{$\begin{array}{c}\text { Standardized } \\
\text { Coefficients } \\
\text { Beta }\end{array}$} & \multirow[t]{2}{*}{$\mathrm{t}$} & \multirow[t]{2}{*}{ Sig. } & \multirow{9}{*}{$\begin{array}{c}\mathrm{R}^{2} \\
0.225\end{array}$} \\
\hline & & B & Std. Error & & & & \\
\hline \multirow[t]{7}{*}{1} & (Constant) & 23.238 & 33.210 & & .700 & .486 & \\
\hline & group & -23.584 & 4.814 & -.453 & -4.899 & .000 & \\
\hline & sex & 5.522 & 4.855 & .105 & 1.137 & .258 & \\
\hline & age & -1.906 & 2.084 & -.169 & -.914 & .363 & \\
\hline & BMI & 1.850 & 1.631 & .209 & 1.134 & .260 & \\
\hline & PR & .115 & .141 & .076 & .817 & .416 & \\
\hline & $\mathrm{Hb}$ & .676 & 1.851 & .034 & .365 & .716 & \\
\hline
\end{tabular}

a. Dependent Variable: QTcd

\section{$P^{*}$ Multi linear regression}

The aforementioned model also revealed that there was a significance between the groups in terms of QTed levels even after matching with all variables such as age, gender, BMI, PR intervals and base hemoglobin levels, and these variables could have influences on this relationship $(\mathrm{P}<0.225)$.

\section{Discussion and conclusion:}

Syncope is sudden and transient loss of consciousness followed by prompt recovery without residual loss of function due to transient and global cerebral hypo perfusion. It accounts for $2 \%$ of children's visits to the emergency department. It is more common at the age of 15 to 19 years and almost $50 \%$ of adolescents experience at least one syncope attack. The incidence is gender dependent and is more common among females than males $^{33,34}$. Another study by Aklinf et al. investigated the role of $\mathrm{Hb}$ levels and Iron deficiency anemia on QTd and the onset of breath-holding spells. The results suggested that these factors had no effects on QT dispersion and the onset of breath-holding spells $^{35}$. The QT dispersion indicates the difference in action potentials in different areas of the myocardium. A region with prolonged repolarization is resistant to electrical conductivity and causes the occurrence of a reentry phenomenon ${ }^{35-37}$. Normal values of QT dispersion in adults are between $25-50 \mathrm{~ms}$, which are longer in patients with long QT syndrome and may reach $150-200 \mathrm{~ms}$. It is accepted that QT dispersion of greater than $80-90 \mathrm{~ms}$ is associated with an increased risk of dysrhythmia ${ }^{35}$. The reason was that there was a significant difference between individuals in measuring QT and QTd values. Secondly, none of the patient had proven arrhythmia with increased QT and QTd values in patients with non-cardiac syncope (nervous syncope) ${ }^{36}$. Although its value is higher than the normal values, its increase is far less than the values that are associated with arrhythmia. A study carried out by Movahedian et al. on QT dispersion in children with breath-holding spells in Kashan University of Medical Sciences showed that the values were consistent with the ones obtained in our study ${ }^{37,38}$, which could be indicative of the effects of the differences between the genetic characteristics of patients and the effects on QT interval and its dispersion. In the current study, patients who suffered from syncope attacks were compared with the control group. Although the obtained values were not consistent with the study accomplished by Vialle, there was a significant difference between them.

In addition to the differences between individuals in measuring QT values and its distribution, the amount of the 
values is also affected by sinus arrhythmia and a significant difference is observed after correcting the QT value based on the heart rate and using Bazett's Formula in people with such arrhythmias ${ }^{33,39,40}$. Increases in parasympathetic tone and deceases in the sympathetic tone are associated with prolongation of QTc values, but there is a controversy over its effect on QTd values ${ }^{41}$. It has been evident that the disruption of the autonomic nervous system is associated with increased QTd in diabetics and patients with primary autonomic disorders ${ }^{26}$. Therefore, Akalin et al., investigated changes in QT and QTed levels in patients with breath-holding spells and concluded that if QT and QTc levels are not increased in the patient at risk of breath-holding spells, the increased QTd interval cannot be attributed to autonomic dysfunction $^{35}$. Similarly, if there are changes in QT and QTd intervals in ECG of children with a syncope attack(s), we should seek causes with a lower incidence of syncope and, but, with a higher risk. Attempts were made in a study that was performed on patients with aortic stenosis, to predict the occurrence of syncope attacks, complications of aortic stenosis, by measuring the QT dispersion. It was also shown that the maximum QTc and QTc dispersion in patients with stenosis and those with complicated aortic stenosis were equal to $477 \pm 49$ and $60 \pm 13 \mathrm{~ms}$ and $493 \pm 48 \mathrm{~ms}$ and $68 \pm 12 \mathrm{~ms}$, respectively. This suggests that QTc dispersion can predict the occurrence of the syncope attack in patients with aortic valve stenosis ${ }^{42}$. In our study, the case group subjects had significantly more QT dispersion than the control group, however, it has been shown in some previous studies that QT dispersion is prolonged at the time of the syncope attack and normalizes after some time ${ }^{43}$. In our study, all the children were referred several hours and days after the onset of syncope, and suffered from increased QT dispersion at the same time. The reason is that QT dispersion is an approximate measure of total abnormalities during cardiac repolarization period and is affected by factors such as measurement error, type of food consumed and day/night indices, as well as genetics and physiology; therefore the complementary methods should be used for quantifying repolarization abnormalities such as T-wave analysis, T-wave morphology, etc. ${ }^{44}$.

\section{Conclusion}

Performing the electrocardiography and examining the QT interval and other related indices in children with syncope attack is an important method to confirm the diagnosis and predict the incidence of subsequent attacks. Prolongation of the QT interval, and especially the increased QT dispersion, should be carefully measured and documented in all.

\section{Conflict of interest}

The authors do not have any conflict of interest including financial in publication of this article.

\section{References}

1. Colman Nl, Bakker A, Linzer M, et.al. Value of history-taking in syncope patients: in whom to suspect long QT syndrome? Europace. 2009. https://doi.org/10.1093/europace/eup101

2. Mathias CJ, Deguchi K, Schatz I. Observations on recurrent syncope and presyncope in 641 patients. Lancet. 2001;357:348-53. https://doi.org/10.1016/S0140-6736(00)03642-4

3. Day SC, Cook EF, Funkenstein H, Goldman L. Evaluation and outcome of emergency room patients with transient loss of consciousness. Am J Med. 1982; 73: 15-23. https://doi.org/10.1016/0002-9343(82)90913-5
4. Kapoor WN, Smith MA, Miller NL. Upright tilt testing in evaluating syncope: a comprehensive literature review. Am J Med. 1994;97: 78-88 https://doi.org/10.1016/0002-9343(94)90051-5

5. Silverstein MD, Singer DE, Mulley AG, Thibault GE, Barnett GO. Patients with syncope admitted to medical intensive care units. JAMA. 1982;248: 1185-89. https://doi.org/10.1001/jama.1982.03330100023024

6. Martin GJ, Adams SL, Martin HG, et.al. Prospective evaluation of syncope. Ann Emerg Med. 1984; 13:499-504. https://doi.org/10.1016/S0196-0644(84)80511-9

7. Ben-Chetrit E, Flugelman M, Eliakim M. Syncope: a retrospective study of 101 hospitalized patients. Isr J Med Sci. 1985;21:950-53.

8. Brignole M, Alboni P, Benditt D, et.al., Thomsen P.E.B. Guidelines on management (diagnosis and treatment of syncope. Eur Heart J. 2004; 25: 2054-72. https://doi.org/10.1016/j.ehj.2004.09.004

9. Lipsitz LA, Pluchino FC, Wei JY, Rowe JW. Syncope in institutionalized elderly: the impact of multiple pathological conditions and situational stress. J Chronic Dis. 1986;39:61930. https://doi.org/10.1016/0021-9681(86)90187-6

10. Kapoor WN. Evaluation and outcome of patients with syncope. Medicine (Baltimore). 1990;69: 160-75. https://doi.org/10.1097/00005792-199005000-00004

11. Strickberger S.A, Benson D.W, Biaggioni I, et.al. A AHA/ ACCF Scientific Statement on the evaluation of syncope. Circulation. 2006;113: 316-27. https://doi.org/10.1016/j. jacc.2005.12.019

12. Gabayan GZ, Derose SF, Asch SM, et.al. Predictors of shortterm (seven-day) cardiac outcomes after emergency department visit for syncope. Am J Cardiol. 2010;105: 82-6. https://doi.org/10.1016/j.amjcard.2009.08.654

13. Fazelifar AF, Ashrafi P, Haghjoo M, et.al. Predictors of ventricular tachycardia induction in syncopal patients with mild to moderate left ventricular dysfunction. Cardiol J. 2009;16: $327-31$.

14. Kurl S, Makikallio TH, Rautaharju P et.al.. Duration of QRS complex in resting electrocardiogram is a predictor of sudden' cardiac death in men. Circulation. 2012; 125:258894.

https://doi.org/10.1161/CIRCULATIONAHA.111.025577

15. Lai HM, Aronow WS, Rachdev A, et.al. Incidence of mortality in 1,040 patients with coronary heart disease or hypertensive heart disease with normal and abnormal left ventricular ejection fraction and with normal and abnormal QRS duration. Archives of Medical Science. 2008 Apr $1 ; 4(2): 140$.

16. Kannam H, Aronow WS, Chilappa K, et.al. Association of the QRS duration on the resting electrocardiogram with the severity of coronary artery disease in 2,196 patients undergoing coronary angiography for suspected coronary artery disease. Arch Med Sci 2009; 5: 163-5.

17. Whang W, Shimbo D, Levitan EB, et.al. Relations between $\mathrm{QRS} \backslash \mathrm{T}$ angle cardiac risk factors, and mortalityin the third national health and nutrition examination survey (NHANES III). Am J Cardiol. 2012;109: 981-7. https://doi.org/10.1016/j.amjcard.2011.11.027

18. Lown MT, Munyombwe T, Harrison W, et.al. Evaluation of Methods and Management of A Association of frontal QRS-T angle: age risk score on admission electrocardiogram with mortality in patients admitted with an acute coronary syndrome. Am J Cardiol. 2012;109: 307-13. https://doi.org/10.1016/j.amjcard.2011.09.014

19. Aggarwal A, Sherazi S, Levitan B, et.al. Corrected QT interval as a predictor of morality in elderly patients with 
syncope. Cardiol J. 2011;18: 395-400.

20. Giunti S, Gruden G, Fornengo P, Barutta F, Amione C, Ghezzo G. Increased QT interval dispersion predicts 15year cardiovascular mortality in type 2 diabetic subjects: the population-based Casale Monferrato study. Diabetes Care. 2012; 35:581-3. https://doi.org/10.2337/dc11-1397

21. Okin PM, Devereux RB. Assessment of QT interval and QT dispersion for prediction of all-cause and cardiovascular mortality in american indians: the Strong Heart study. Howard BV Circulation. 2000; 101: 61-6. https://doi.org/10.1161/01.CIR.101.1.61

22. Tsuji H, Venditti FJ Jr, Manders ES, et.al. Reduced heart rate variability and mortality risk in an elderly cohort. Circulation 1994;90: 878-83. https://doi.org/10.1161/01.CIR.90.2.878

23. Kathryn ML. Defining the role of dialysate Magnesium in Arrythmogenicity on Dialysis Clinic trialgov 2005;21 (2): 186-92.

24. Sakai Y, Sakai S, Ohtsuka T, Ohno D, Amitani K, Ono T, et al. QT dispersion increases during hemodialysis procedures in patients undergoing maintenance dialysis:-association with an RA system and holter electrocardiogram. Nihon Jinzo Gakkai Shi. 2008; 50(4):481-7.

25. Yildiz A, Akkaya V, Sahin S, Tukek T, Besler M, Bozfakioglu $\mathrm{S}$, et al. QT dispersion and signal averaged electrocardiogram in hemodialysis and CAPD patients. Perit Dial In. 2001; 21 (2): 186-92.

26. Rossing P, Breum L, Major-Pedersen A, et.al. Prolonged QTC interval predicts mortality in patients with type 1 diabetes mellitus. Diabet Med. 2001;18: 199-205. https://doi.org/10.1046/j.1464-5491.2001.00446.x

27. Dekker LM, Schouten EG, Klootwijk P, et.al. Association between QT interval and coronary heart disease in middleaged and elderly men. Circulation. 1994; 90:779-85. https://doi.org/10.1161/01.CIR.90.2.779

28. Goldberg RJ, Bengston J, Chen ZY, et.al. Duration of the QT interval and total and cardiovascular mortality in healthy persons (the Framingham Heart Study experience). Am J Cardiol. 1991;67: 55-8.

https://doi.org/10.1016/0002-9149(91)90099-7

29. Vrtovec B, Delgado R, Zewail A, et.al. Prolonged QTC interval and high B-type natriuretic peptide levels together predict mortality in patients with advanced heart failure. Circulation. 2003;107: 1764-9. https://doi.org/10.1161/01.CIR.0000057980.84624.95

30. Jha OPl, Khurana DS, Carvalho KS, et.al. Assessment of the QT interval in the electroencephalography (EEG) of children with syncope, epilepsy, and attention-deficit hyperactivity disorder (ADHD). Child Neurol. 2010 25(3):284-6.
31. Liu JFl, Jons C, Moss AJ, et al. Risk factors for recurrent syncope and subsequent fatal or near-fatal events in children and adolescents with longQT syndrome. J Am Coll Cardiol. 2011 57(8):941-50. https://doi.org/10.1016/j.jacc.2010.10.025

32. Colman N, Nahm K, Ganzeboom KS, et.al. Epidemiology of reflex syncope. Clin Auton Res. 2004;14:9-17. https://doi.org/10.1007/s10286-004-1003-3

33. Mace S, Schrieber DH. syncope in pediatric patients. AHC Media. 2010;feb.

34. Srivastava D, Misra R, Prakash A, Gautam P, Dutta S. Correction of anthropometric parameters with QTc interval in malnourished children. Indian J Physiol Pharmacol. 2011;55:37-43.

35. Akalin F, Turan S, Güran T, Ayabakan C, Yilmaz Y. Increased QT dispersion in breath-holding spells. Acta paediatr. 2004;93:770-4. https://doi.org/10.1111/j.1651-2227.2004.tb03016.x

36. Kocak G, yurdakul M, Gurses D, Ergin H. QT interval and dispersion in malnourished children. Turgut Ozal Tip Merkezi Dergisi. 2001;7:128-11.

37. Higham PD, Campbell RWF. QT dispersion. Br Heart J. 1994;71:508-10. https://doi.org/10.1136/hrt.71.6.508

38. Movahedian AH, Heidarzadeh arani M, Motaharizad D, et.al. Evaluation of QT dispersion in children with breath holding spells. Iran J Child Neurol. 2016;10(1):25-30.

39. Tutar HE, Ocal B, Imamoglu A, Atalay S. Dispersion of QT and QTc interval in healthy children,an effects of sinus arrythmia on QT dispersion. Heart. 1998;80:77-9. https://doi.org/10.1136/hrt.80.1.77

40. Day CP, McComb JM, Campbell RW. QT dispersion: an indication of arrhythmia risk in patients with long QT intervals. Heart. 1990 Jun 1;63(6):342-4. https://doi.org/10.1136/hrt.63.6.342

41. Monfared A, Zahra Atrkar Roshan Z, Salari A, Asadi F, Lebadi MK, Khosravi M, et al. QT Intervals in Patients Receiving a Renal Transplant. Exp \& Clin Transplant. 2012;10,(2). https://doi.org/10.6002/ect.2011.0117

42. Koşar F, Hisar I, Durmaz T, Ileri M, I. T. QTc dispersion measurement for risk of syncope in patients with aortic stenosis. Angiology. 2001; 52: 259-65. https://doi.org/10.1177/000331970105200405

43. Dragon D, Marina D I, Ivan T. Nearly two decades of QTc dispersion in cardiology. Medicine and Biology. 2007;3:10711.

44. Parchure N, Batchvarov V, Malik M, et.al. QT dispersion in patients with prinzmetals variant angina and cardiac arrest. cardiovascular research. 2001;50: 379-85. https://doi.org/10.1016/S0008-6363(00)00290-X 